\title{
Apolipoprotein E4 and psoriasis
}

\author{
Hong-Liang Zhang $\cdot$ Jiang Wu
}

Received: 18 November 2009/ Accepted: 8 December 2009/Published online: 23 December 2009

(C) Springer-Verlag 2009

To the Editor,

We read with great interest the recent article by CotoSegura et al. [2] about the association of apolipoprotein E (APOE) $\varepsilon 4$ allele and psoriasis (Ps). Although allele and genotype frequencies of apolipoprotein $\mathrm{E}$ (apoE) did not differ between Ps patients and controls, a positive correlation between APOE $\varepsilon 4$ allele and Ps severity appeared intriguing in that such an association might justify apoE as a therapeutic target for psoriasis in future. We agree that more studies on different populations are necessary to confirm this association, while we would like to point out one pitfall of the study.

ApoE is a $34.2 \mathrm{kDa}$ glycoprotein characterized by its wide tissue distribution and multiple properties. The chromosome $19 \mathrm{q} 13$, on which APOE $\varepsilon$ lies, has been suggested to be involved in autoimmune diseases such as systemic lupus erythematosus [8]. Furthermore, an increasing body of evidence points to the association of APOE $\varepsilon 4$ with human diseases such as multiple sclerosis [7], cardiovascular diseases [6], and Alzheimer's disease [5]. However, Coto-Segura et al. excluded patients with diabetes, or hypertension, or coronary heart diseases, or Alzheimer's disease from the control group. The exclusion might consequently result in a reduced allele frequency of APOE $\varepsilon 4$ in non-Ps population, thus leading to false positive in their study. From epidemiological investigations, either ethnical

H.-L. Zhang · J. Wu

Department of Neurology, The First Hospital of Jilin University, Changchun, China

\section{H.-L. Zhang ( $₫)$}

Department of Neurobiology, Care Sciences and Society, Karolinska Institute, Novum, plan 5, Geriatric Lab, Huddinge, 14186 Stockholm, Sweden

e-mail: Hongliang.Zhang@ki.se or geographical difference has been proposed in APOE genotype distribution in healthy population [3, 4]. And so does the incidence of the above diseases. In this regard, linkage analysis of APOE $\varepsilon$ involving both positive and negative controls may be of help to avert the impact of such confounding factors [1]. In summary, it is appealing that APOE $\varepsilon 4$ is associated with Ps, and may act as a therapeutic target in future, although more large-scale, populationbased studies are still needed.

\section{References}

1. Bianca S, Barrano B, Cutuli N et al (2009) No association between apolipoprotein $\mathrm{E}$ polymorphisms and recurrent pregnancy loss. Fertil Steril. doi:10.1016/j.fertnstert.2009.07.971

2. Coto-Segura P, Coto E, Alvarez V et al (2009) Apolipoprotein epsilon4 allele is associated with psoriasis severity. Arch Dermatol Res. doi: 10.1007/s00403-009-1002-2

3. Gerdes LU (2003) The common polymorphism of apolipoprotein E: geographical aspects and new pathophysiological relations. Clin Chem Lab Med 41:628-631

4. Gerdes LU, Klausen IC, Sihm I et al (1992) Apolipoprotein E polymorphism in a Danish population compared to findings in 45 other study populations around the world. Genet Epidemiol 9:155-167

5. Kim J, Basak JM, Holtzman DM (2009) The role of apolipoprotein E in Alzheimer's disease. Neuron 63:287-303

6. Knopman DS, Roberts RO, Geda YE et al (2009) Association of prior stroke with cognitive function and cognitive impairment: a population-based study. Arch Neurol 66:614-619

7. Mazurek AA, Shi J (2008) APOE epsilon4 allele is associated with cognitive impairment in patients with multiple sclerosis. Neurology $71: 1203$

8. Xing C, Sestak AL, Kelly JA et al (2007) Localization and replication of the system lupus erythematosus linkage signal at 4p16: interaction with 2p11, 12q24, and $19 \mathrm{q} 13$ in European Americans. Hum Genet 120:623-631 